\title{
Evaluations for service-sire conception rate for heifer and cow inseminations with conventional and sexed semen
}

\author{
H. D. Norman, ${ }^{1}$ J. L. Hutchison, and P. M. VanRaden \\ Animal Improvement Programs Laboratory, Agricultural Research Service, USDA, Beltsville, MD 20705-2350
}

\begin{abstract}
Service-sire conception rate (SCR), a phenotypic fertility evaluation based on conventional (nonsexed) inseminations from parities 1 through 5, was implemented for the United States in August 2008. The SCR model contains the categorical fixed effects of parity for lactations 1 to 5; state-year-month of insemination group; 6 standardized milk yield groups; service number for inseminations 1 to 7; cow age; and herd-yearseason-parity-registry status class. Covariate effects for service-sire and mating inbreeding coefficients were linear regressions fit as deviations from the overall mean. Random effects included service-sire age group; AI organization-insemination year group; individual service sire; cow's genetic ability to conceive; cow's permanent environmental effect; and residual. Using insemination data from 2005 through 2009, the SCR procedure was applied separately for nulliparous heifer inseminations with conventional semen $\left(\mathrm{SCR}_{\mathrm{H}_{\text {conv }}}\right)$, cow inseminations with conventional semen $\left(\mathrm{SCR}_{\mathrm{C}_{\text {conv }}}\right)$, nul-
\end{abstract} liparous heifer inseminations with sexed semen $\left(\mathrm{SCR}_{\mathrm{H}_{\text {sexed }}}\right)$, and cow inseminations with sexed semen $\left(\mathrm{SCR}_{\mathrm{C}_{\text {sexed }}}\right)$. Holstein and Jersey bulls with $\geq 300$ and $\geq 200$ artificial inseminations, respectively, in $\geq 10$ herds and with $\geq 100$ breedings during the 12 mo before evaluation were examined. The number of bulls evaluated for SCR in January 2010 was 270 Holsteins and 16 Jerseys for $\mathrm{SCR}_{\mathrm{H}_{\text {conv }}}, 2,309$ Holsteins and 214 Jerseys for $\mathrm{SCR}_{\mathrm{C}_{\text {conv }}}, 114$ Holsteins and 6 Jerseys for $\mathrm{SCR}_{\mathrm{H}_{\text {sexed }}}$, and 25 Holsteins and 7 Jerseys for $\mathrm{SCR}_{\mathrm{C}_{\text {sexed }}}$. The mean SCR for each evaluation category was set to 0; Holstein standard deviations were $2.55 \%$ for $\mathrm{SCR}_{\mathrm{H}_{\text {conv }}}, 2.21 \%$ for $\mathrm{SCR}_{\mathrm{C}_{\text {conv }}}, 4.29 \%$ for $\mathrm{SCR}_{\mathrm{H}_{\text {sexed }}}$, and $2.39 \%$ for $\mathrm{SCR}_{\mathrm{C}_{\text {sexed }}}$. The mean Holstein reliabilities were 82, 79, 75, and $73 \%$, respectively. Correlations for Holstein SCR between conventional and sexed semen averaged near zero $(-0.21$ to 0.18$)$. Predicted correlations between true

Received September 29, 2010.

Accepted August 5, 2011.

${ }^{1}$ Corresponding author: Duane.Norman@ars.usda.gov
SCR were -0.27 to 0.24 . In contrast, correlations between Holstein heifers and cows were high (0.66 to $0.76)$, and predicted true correlations averaged near 1.0 (0.82 to 1.03). Correlations for Jerseys were often larger, although based on fewer inseminations and service sires compared with Holsteins. Some rankings for SCR could benefit from combining cow and heifer data but should be kept separate for conventional and sexed semen inseminations.

Key words: service sire, conception rate, sexed semen, bull fertility

\section{INTRODUCTION}

Dairy producer interest in sexed semen has been based largely on a desire to obtain more heifer calves for herd growth while maintaining a closed herd, supply herd replacements for other producers, or accelerate genetic improvement within the herd. Norman et al. (2010) documented the rapid acceptance of sexed semen technology in DHI herds in the United States. They also reported differences in conception rate, dystocia, stillbirth, and calf sex from using femaledesignated sexed semen versus conventional (nonsexed) semen for breeding heifers and cows. Compared with conventional semen, the conception rate for sexed semen was $70 \%$ as high for heifer breedings and $83 \%$ as high for cow breedings. Those national findings were similar to earlier results from field trials (Seidel and Schenk, 2002; DeJarnette et al., 2009; Schenk et al., 2009). For female-designated sexed semen, female calves resulted from $91 \%$ of heifer inseminations and $89 \%$ of cow inseminations; corresponding percentages for conventional semen were 51 and 48 (Norman et al., 2010). The slightly higher percentage of female than male calves for nulliparous heifers bred with conventional semen could be the result of incorrect coding of some sexed semen or an underlying physiological circumstance (Skjervold and James, 1979). Norman et al. (2010) also reported that dystocia was decreased by $28 \%$ for heifers and $64 \%$ for cows through the use of female-designated sexed semen. In contrast, they reported that stillbirths were more prevalent for heifers from sexed than from conventional semen (9\%) but 
less prevalent for cows $(25 \%)$. The surprising frequency in stillbirths for heifers from female-designated sexed semen resulted primarily from a $44 \%$ higher stillbirth incidence for single male calves than for single female calves, but stillbirth incidence also was $11 \%$ higher for single female calves. DeJarnette et al. (2009) first reported an unusually high incidence of stillbirths with male calves when female-designated sexed semen was used.

Field trials with sexed semen have shown unpredictable bull differences in fertility after sperm is sex sorted compared with the fertility before sorting (Seidel and Schenk, 2002; i.e., the sperm of some bulls tolerates the stress of sex sorting better than that of other bulls). DeJarnette et al. (2009) and Abdel-Azim (2010) reported that separate conception rates for conventional and sexed semen were essential for bull rankings.

Service-sire differences in fertility of conventional semen have been documented and bull rankings for nonreturn rate made available from 1986 through 2005 by North Carolina State University and Dairy Records Management Systems (Raleigh, NC; Clay, 1987). The Western Fertility Analysis, a service-sire ranking based on conception rates for confirmed pregnancies from conventional semen, was initiated in 2000 through AgriTech Analytics (Visalia, CA; Weigel, 2006).

A national evaluation for service-sire conception rate (SCR) was implemented in August 2008 by the USDA Animal Improvement Programs Laboratory (Beltsville, MD; Norman et al., 2008a). This phenotypic bull fertility evaluation based on inseminations with conventional semen was the culmination of research reported by Kuhn et al. (2006, 2008) and Kuhn and Hutchison (2008). An SCR evaluation is the difference in probability that a unit of semen from a specific bull will result in a pregnancy compared with the mean of all other bulls that could have been used. In developing SCR Kuhn and Hutchison (2008) compared results from both the categorical and linear model and found linear models were as effective as threshold models in determining the usefulness of multiple services and expanded service sire terms. Linear models were used to avoid the substantial computing time required to obtain categorical evaluations and minimize the complexity of results.

Only AI inseminations from the first 7 breedings with known outcomes (success or failure) are included in SCR. All information reported subsequently, such as additional inseminations, future calving dates, pregnancy check reports, do-not-breed designations, and termination codes, were used in determining pregnancy status for each insemination. These edits are the reason that SCR is considered a conception rate evaluation rather than an evaluation based on nonreturn rate. To date, the official SCR evaluations have not been expanded to include results from sorted semen because commercial use of the technology only started in 2006 .

The objective of this study was to compare separate SCR evaluations for cow and heifer inseminations with conventional or sexed semen to determine whether dairy producers can be provided more accurate predictions of bull fertility in different breeding situations.

\section{MATERIALS AND METHODS}

Holstein and Jersey records for AI breedings with conventional or sexed semen were extracted from the US national dairy database (Beltsville, MD). Sexed semen use was determined from coding in reproductive records (format 5; Animal Improvement Programs Laboratory, 2009) supplied to the USDA by dairy records processing centers: either AI breeding with gender-selected semen (code G) for type of reproductive event or a semen-processing organization code from the National Association of Animal Breeders (Columbia, MO), generally in the 500 series (semen marketing codes). The reproductive records were supplied to the national database primarily from AgSource Cooperative Services (Verona, WI), AgriTech Analytics (Visalia, CA), and Dairy Records Management Systems (Raleigh, NC, and Ames, IA). Those 3 dairy records processing centers provided $>1.5$ million breeding records for heifers and $>13.1$ million breeding records for cows. Records with a semen marketing code of 514 were excluded from analysis because the technology used by Accelerated Genetics (Baraboo, WI) differed from that used by other AI organizations.

The Council on Dairy Cattle Breeding oversees a quality certification program for the US dairy industry and, through an agreement with the USDA Animal Improvement Programs Laboratory, agrees to provide data so that accurate genetic evaluations will be provided to the dairy industry on a routine basis. Using the US procedure designed for official SCR evaluations (Norman et al., 2008a), 4 separate SCR evaluations were calculated based on independent sources of input data. The 4 separate SCR categories were nulliparous heifer inseminations with conventional semen $\left(\mathbf{S C R}_{\mathbf{H}_{\text {conv }}}\right)$, cow inseminations with conventional semen $\left(\mathbf{S C R}_{\mathrm{C}_{\text {conv }}}\right)$, nulliparous heifer inseminations with sexed semen $\left(\mathbf{S C R}_{\mathbf{H}_{\text {sexed }}}\right)$, and cow inseminations with sexed semen $\left(\mathbf{S C R}_{\mathrm{C}_{\text {sexed }}}\right)$. The $\mathrm{SCR}_{\mathrm{C}_{\text {conv }}}$ evaluation was identical to the US official SCR evaluation that is released to the dairy industry. Data edits were primarily the same as for US official SCR evaluations (Kuhn et al., 2008; Norman et al., 2008a). Age at breeding was restricted to $\geq 12$ and $<27$ mo for nulliparous heifers and $\geq 22$ mo 
and $<15$ yr for cows. For cows, the first 7 inseminations from parities 1 through 5 were included, and standardized milk yield had to exceed 4,536 $\mathrm{kg}$ for Holsteins and $2,722 \mathrm{~kg}$ for Jerseys. In addition, lactation length at breeding was limited to 30 to 365 DIM. Inseminations were excluded for any lactation for which the animal was coded as an embryo transfer donor. When the interval between 2 inseminations was $<10 \mathrm{~d}$, information from the later service was kept, and the earlier service was not considered when assigning subsequent service numbers for the same lactation. Breedings were restricted to purebred matings. Additional restrictions based on herd edits were the same as described by Norman et al. (2008b, 2010).

Only inseminations from the most recent 4 yr of reported breedings were used to compute an August 2009 and January 2010 SCR for each evaluation category. Holstein and Jersey bulls with $\geq 300$ and $\geq 200$ AI, respectively, in $\geq 10$ herds and with $\geq 100$ breedings during the 12 mo before August 2009 or January 2010 were studied. To be included, all inseminations were required to be $\geq 70 \mathrm{~d}$ before the data submission deadline for the corresponding US official evaluation, and calving date was required to be $\geq 100 \mathrm{~d}$ before data submission deadline. Without these edits, animals appearing within these time periods would not have had adequate time for rebreeding and pregnancy check, and therefore, the outcome of services would not have been coded accurately (successful or not). No positive or negative diagnoses occurring during the interval were included before completion of this designated time period. The number of inseminations available for each SCR category is in Table 1 by evaluation date. Most of the reported inseminations (88\%) were from conventional semen for cow breedings within each evaluation run for both Holsteins and Jerseys. Heifer breedings using conventional semen accounted for $10 \%$ of Holstein inseminations and $9 \%$ of Jersey inseminations within each evaluation run, and sexed semen accounted for only $2 \%$ of Holstein and $3 \%$ of Jersey inseminations.

Evaluations for SCR were calculated within breed and included 13 model effects to define characteristics of both service sire and cow or heifer for predicting SCR (Norman et al., 2008a,b), with some slight varia- tion among models. Categorical cow or heifer fixed effects were included for parity (1 through 5 for cows); service number (1 through 7 ); herd-year-season-parityregistry status class; state-year-month of breeding group; age of heifer at breeding rounded to the nearest tenth of a year $(1.0,1.1 ., \ldots \geq 2.0)$ or age of cow at breeding rounded to the nearest integer $(2,3, \ldots \geq 8$ yr); code for short breeding interval of 10 to $17 \mathrm{~d}$; and 6 standardized milk yield groups (for cows). Covariate effects for service-sire and embryo inbreeding coefficients were linear regressions fit as deviations from overall mean. Random effects included service-sire age at breeding (12 Holstein and 9 Jersey groups for $\mathrm{SCR}_{\mathrm{C}_{\text {conv }}}$ and 1 to 2 groups for the other SCR categories because of the limited number of bulls; Table 2), AI organization assigned to the bull-insemination year (4 rolling year groups), individual service sire, genetic ability of cow or heifer to conceive, permanent environmental effect for cow or heifer, and residuals. Variance estimates for the random effects were obtained by Kuhn et al. (2008). Mean SCR within category were forced to sum to 0 .

Artificial insemination organization coding was based on the marketing organizations. It is likely that considering both the processing and marketing organizations would have added to the accuracy had the information been available for each. It is unfortunate that the processing date was not available also, as the age of the bull when semen was produced should be more effective than the age of the bull when the insemination occurred.

Correlations between the 4 SCR categories were calculated for each evaluation date (August 2009 and January 2010) and also across evaluation dates. Correlations derived from evaluations with reliability less than 1 generally underestimate the true positive or negative correlations that would have occurred had they been based on large numbers. Therefore, the method of Calo et al. (1973) was used to adjust for the expected shrinkage to improve the probability of revealing the true relationship between semen types for the service sires. Estimated correlations between true SCR $\left(\mathbf{r}_{\mathbf{t}}\right)$ were calculated from observed SCR correlations:

Table 1. Number of inseminations by breed and evaluation date for 4 evaluation categories of service-sire conception rate $(\mathrm{SCR})$ based on animal parity [nulliparous heifer $(\mathrm{H})$ or cow $(\mathrm{C})$ ] and type of semen used for breeding [conventional (conv) or sexed]

\begin{tabular}{llrrrr}
\hline \multirow{2}{*}{ Breed } & Evaluation & & & & \\
& date & $\mathrm{SCR}_{\mathrm{H}_{\text {conv }}}$ & $\mathrm{SCR}_{\mathrm{C}_{\text {conv }}}$ & $\mathrm{SCR}_{\mathrm{H}_{\text {sexed }}}$ & $\mathrm{SCR}_{\mathrm{C}_{\text {sexed }}}$ \\
\hline \multirow{2}{*}{ Holstein } & August 2009 & $1,583,126$ & $13,213,126$ & 189,526 & 56,994 \\
& January 2010 & $1,515,395$ & $13,216,858$ & 222,988 & 58,876 \\
\multirow{2}{*}{ Jersey } & August 2009 & 62,530 & 607,552 & 8,450 & 14,465 \\
& January 2010 & 63,285 & 634,728 & 10,923 & 16,314 \\
\hline
\end{tabular}


Table 2. Definition of bull age groups by breed ${ }^{1}$ for 4 evaluation categories of service-sire conception rate $(\mathrm{SCR})$ based on animal parity [nulliparous heifer $(\mathrm{H})$ or cow $(\mathrm{C})$ ] and type of semen used for breeding [conventional (conv) or sexed]

\begin{tabular}{|c|c|c|c|c|c|}
\hline \multirow{3}{*}{$\begin{array}{l}\text { Bull age } \\
\text { group }\end{array}$} & \multicolumn{5}{|c|}{ Service-sire age (yr) } \\
\hline & \multirow[b]{2}{*}{$\mathrm{SCR}_{\mathrm{H}_{\text {conv }}}$} & \multicolumn{2}{|c|}{$\mathrm{SCR}_{\mathrm{C}_{\text {conv }}}$} & \multirow[b]{2}{*}{$\mathrm{SCR}_{\mathrm{H}_{\text {sexed }}}$} & \multirow[b]{2}{*}{$\mathrm{SCR}_{\mathrm{C}_{\text {sexed }}}$} \\
\hline & & Holstein & Jersey & & \\
\hline 1 & $0.8-7.5$ & $0.8-1.3$ & $0.8-1.0$ & $0.8-7.5$ & $\geq 0.8$ \\
\hline 2 & $>7.5$ & $1.4-1.5$ & $1.1-2.0$ & $>7.5$ & \\
\hline 3 & & $1.6-1.7$ & $2.1-4.0$ & & \\
\hline 4 & & $1.8-2.0$ & $4.1-5.0$ & & \\
\hline 5 & & $2.1-4.5$ & $5.1-6.0$ & & \\
\hline 6 & & $4.6-5.5$ & $6.1-7.0$ & & \\
\hline 7 & & $5.6-6.5$ & $7.1-8.0$ & & \\
\hline 8 & & $6.6-7.5$ & $8.1-9.0$ & & \\
\hline 9 & & $7.6-8.5$ & $>9.0$ & & \\
\hline 10 & & $8.6-9.5$ & & & \\
\hline 11 & & $9.6-10.5$ & & & \\
\hline 12 & & $>10.5$ & & & \\
\hline
\end{tabular}

$$
\mathrm{r}_{\mathrm{t}}=r_{A B} / \sqrt{\left(R E L_{A} / 100\right)\left(R E L_{B} / 100\right)},
$$

where $A$ and $B$ are the 2 SCR categories being compared and $R E L$ is the reliability for $\mathrm{SCR}[R E L=\mathrm{n} /$ $(\mathrm{n}+260)$, where $\mathrm{n}$ is the number of inseminations and the constant 260 was derived by including all random effects in the expanded service-sire term]. Although the absolute values of $r_{t}$ cannot exceed 1.0 in actuality, they were reported as estimated. Confidence limits (95\%) were presented for all correlations.

To determine whether data should be combined across parities to attempt to improve accuracy, alternative SCR were evaluated in 2 ways. First, heifer and cow inseminations were analyzed together in the official SCR model, after predicted milk yield (derived from heifer parent information) was substituted into the same grouping category as for standardized milk yield when used for a cow insemination. Pedigree predicted milk yield was the sum of the mean standardized milk yield of cows in the herd and the parent average milk of the heifer. Second, each service sire's heifer and cow SCR were combined through weighting by the reliability of each after they were derived from the separate data sets. Another alternative approach might have been tried with an interaction effect between sires and semen categories added to the official SCR model, but this was not done.

\section{RESULTS AND DISCUSSION}

Summary statistics for the 4 SCR categories are in Table 3 by breed and evaluation date. The most substantial source of information was $\mathrm{SCR}_{\mathrm{C}_{\text {conv }}}$, which is the same as the US official SCR evaluation; it provided $85 \%$ of Holstein bulls' SCR and 86 to $88 \%$ of Jersey bulls' SCR evaluations. An additional 10\% of Holstein bulls with SCR and 7 to $8 \%$ of Jersey bulls with SCR evaluations were from $\mathrm{SCR}_{\mathrm{H}_{\text {conv }}}$. Only $5 \%$ of Holstein bulls and 5 to $6 \%$ of Jersey bulls with SCR were based on inseminations with sexed semen. Sexed semen SCR derived from heifers would be more advantageous than based on cows because 3 times as many evaluations were available. For heifer data in January 2010 from both Holsteins and Jerseys, the mean number of inseminations per bull was higher for conventional semen (3,321 and 972, respectively) than sexed semen $(1,313$ and 696). As a result, mean SCR reliabilities for conventional semen were generally about 7 percentage units higher than SCR reliabilities for sexed semen. Because only $9 \%$ as many Jersey bulls with 24 to $59 \%$ as many inseminations per bull were evaluated compared with Holsteins, mean SCR reliabilities were lower for Jerseys than for Holsteins.

Mean SCR for all categories (Table 3) was 0, as expected. However, Holstein standard deviations for $\mathrm{SCR}_{\mathrm{H}_{\text {sexed }}}$ were larger (4.29 to 5.76) than for other SCR categories (2.21 to 2.59). The larger standard deviations for sexed semen seem to suggest that fertility is less predictable after sorting, in agreement with Seidel and Schenk (2002). Jersey standard deviations generally were lower than Holstein standard deviations (6 of 8 ), and their standard deviation for $\mathrm{SCR}_{\mathrm{H}_{\text {sexed }}}$ was more similar to other SCR categories. However, these were based on few bulls and fewer inseminations per bull. Bull residual is the primary component of SCR; statistics for bull residual were examined. January 2010 
Table 3. Summary statistics for bulls by breed and evaluation date for 4 evaluation categories of service-sire conception rate (SCR) based on animal parity [nulliparous heifer $(\mathrm{H})$ or cow $(\mathrm{C})$ ] and type of semen used for breeding [conventional (conv) or sexed]

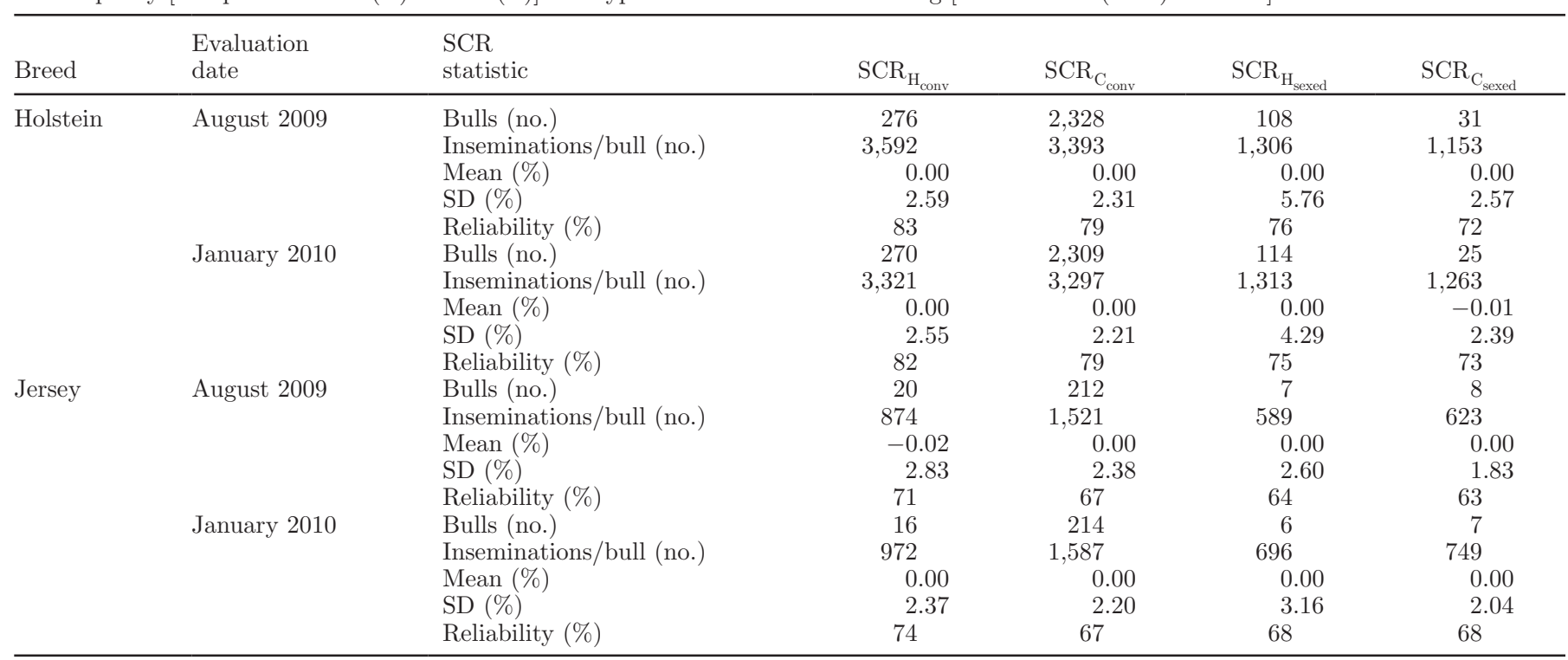

Holstein standard deviations were $2.55,2.21,4.29$, and 2.39 for $\mathrm{SCR}_{\mathrm{H}_{\text {conv }}}, \mathrm{SCR}_{\mathrm{C}_{\text {conv }}}, \mathrm{SCR}_{\mathrm{H}_{\text {sexed }}}$, and $\mathrm{SCR}_{\mathrm{C}_{\text {sexed }}}$, respectively, but were smaller at $2.10,1.97,3.16$, and 2.08 for the residual component, providing 74 to $89 \%$ of the variation in SCR. The correlations between the 2 were $0.88,0.91,0.88$, and 0.93 . Jersey standard deviations for January 2010 were 2.37, 2.20, 3.16, and 2.04 for $\mathrm{SCR}_{\mathrm{H}_{\text {conv }}}, \mathrm{SCR}_{\mathrm{C}_{\text {conv }}}, \mathrm{SCR}_{\mathrm{H}_{\text {sexed }}}$, and $\mathrm{SCR}_{\mathrm{C}_{\text {sexed }}}$, respectively, but were smaller at 1.83, 1.89, 2.06, and 1.48 for the residual component, providing 65 to $86 \%$ of the variation in SCR. The correlations between the 2 were $0.98,0.89,0.87$, and 0.94 .

Holstein correlations (Table 4 ) between $\mathrm{SCR}_{\mathrm{H}_{\text {conv }}}$ and $\mathrm{SCR}_{\mathrm{H}_{\text {sexed }}}$ were -0.21 for August 2009 and 0.08 for January 2010 (based on 86 and 87 bulls, respectively), which resulted in an $r_{t}$ of -0.27 and 0.11 , respectively. Corresponding Holstein correlations between $\mathrm{SCR}_{\mathrm{C}_{\text {conv }}}$ and $\mathrm{SCR}_{\mathrm{C}_{\text {sexed }}}$ were 0.10 and 0.18 (based on 30 and 24 bulls, respectively), producing an $r_{t}$ of 0.14 and 0.24 . The correlations averaged near zero between conventional and sexed semen. Those results support the findings of DeJarnette et al. (2009) and Abdel-Azim (2010) that bull rankings for fertility evaluations based on sexed semen inseminations differ markedly from those based on conventional semen.

Nevertheless, correlations between Holstein $\mathrm{SCR}_{\mathrm{H}_{\text {conv }}}$ and $\mathrm{SCR}_{\mathrm{C}_{\text {conv }}}$ were 0.68 for August 2009 and 0.66 for January 2010 (272 and 259 bulls; $r_{t}$ of 0.85 and 0.82 , respectively); correlations between $\mathrm{SCR}_{\mathrm{H}_{\text {sexed }}}$ and $\mathrm{SCR}_{\mathrm{C}_{\text {sexed }}}$ were 0.73 and 0.76 (26 and 21 bulls; $\mathrm{r}_{\mathrm{t}}$ of 1.00 and 1.03, respectively). Thus, true correlations between Holstein SCR calculated from heifers versus cows averaged 0.92 , raising the probability that combining these might improve their accuracy.

Jersey correlations (Table 4) between $\mathrm{SCR}_{\mathrm{H}_{\text {conv }}}$ and $\mathrm{SCR}_{\mathrm{H}_{\text {sexed }}}$ were 0.30 and 0.70 (based on 6 and 4 bulls, respectively), which resulted in an $\mathrm{r}_{\mathrm{t}}$ of 0.44 and 0.99 , respectively. Corresponding Jersey correlations between $\mathrm{SCR}_{\mathrm{C}_{\text {conv }}}$ and $\mathrm{SCR}_{\mathrm{C}_{\text {sexed }}}$ were 0.74 for August 2009 and 0.65 for January 2010 (based on 8 and 7 bulls, respectively), which resulted in an $\mathrm{r}_{\mathrm{t}}$ of 1.14 and 0.96 . Correlations between Jersey $\mathrm{SCR}_{\mathrm{H}_{\text {conv }}}$ and $\mathrm{SCR}_{\mathrm{C}_{\text {conv }}}$ were 0.76 for August 2009 and 0.54 for January 2010 (20 and 16 bulls; $\mathrm{r}_{\mathrm{t}}$ of 1.10 and 0.77 , respectively); correlations between $\mathrm{SCR}_{\mathrm{H}_{\text {sexed }}}$ and $\mathrm{SCR}_{\mathrm{C}_{\text {sexed }}}$ were 0.88 and 0.82 (4 and 5 bulls; $\mathrm{r}_{\mathrm{t}}$ of 1.38 and 1.22 , respectively). Correlations tended to be higher for Jerseys than for Holsteins but were based on few bulls and inseminations. The 95\% confidence ranges are shown in the bottom of Table 4 and indicate which of the 4 alternatives differ within each breed and evaluation date. This confirms little overlap in the correlation range in Holsteins, with the correlation between heifer and cow evaluations higher than the correlation between conventional and sexed semen evaluations. In Jerseys, the confidence ranges were too wide to draw similar conclusions, possibly due to limited bulls and inseminations per bull.

The correlations in Table 5 generally are as expected considering the correlations in Table 4 and the amount of data unchanged in consecutive evaluation dates. There were $82,85,83$, and $83 \%$ of the same cows in 
Table 4. Correlations and 95\% confidence limits between service-sire conception rate (SCR) with number of bulls in parentheses (above diagonal) and correlations between true SCR (below diagonal) by breed and evaluation date for 4 evaluation categories based on animal parity [nulliparous heifer $(\mathrm{H})$ or cow $(\mathrm{C})$ ] and type of semen used for breeding [conventional (conv) or sexed]

\begin{tabular}{|c|c|c|c|c|c|c|}
\hline Breed & $\begin{array}{l}\text { Evaluation } \\
\text { date }\end{array}$ & $\begin{array}{l}\text { SCR } \\
\text { category }\end{array}$ & $\mathrm{SCR}_{\mathrm{H}_{\text {conv }}}$ & $\mathrm{SCR}_{\mathrm{C}_{\text {conv }}}$ & $\mathrm{SCR}_{\mathrm{H}_{\text {sexed }}}$ & $\mathrm{SCR}_{\mathrm{C}_{\text {sexed }}}$ \\
\hline \multicolumn{7}{|c|}{ Correlation } \\
\hline \multirow[t]{7}{*}{ Holstein } & \multirow[t]{4}{*}{ August 2009} & $\mathrm{SCR}_{\mathrm{H}_{\text {conv }}}$ & & $0.68(272)$ & $-0.21(86)$ & $-0.06(28)$ \\
\hline & & $\mathrm{SCR}_{\mathrm{C}_{\text {conv }}}$ & 0.85 & & $-0.08(90)$ & $0.10(30)$ \\
\hline & & $\mathrm{SCR}_{\mathrm{H}_{\text {sexed }}}$ & -0.27 & -0.10 & & $0.73(26)$ \\
\hline & & $\mathrm{SCR}_{\mathrm{C}_{\text {sexed }}}$ & -0.07 & 0.14 & 1.00 & \\
\hline & \multirow{3}{*}{ January 2010} & $\mathrm{SCR}_{\mathrm{C}_{\text {conv }}}$ & 0.82 & & $0.09(100)$ & $0.18(24)$ \\
\hline & & $\mathrm{SCR}_{\mathrm{H}_{\text {sexed }}}$ & 0.11 & 0.12 & & $0.76(21)$ \\
\hline & & $\mathrm{SCR}_{\mathrm{C}_{\text {sexed }}}$ & 0.20 & 0.24 & 1.03 & \\
\hline \multirow[t]{4}{*}{ Jersey } & \multirow[t]{2}{*}{ August 2009} & $\mathrm{SCR}_{\mathrm{H}_{\text {conv }}}$ & & $0.76(20)$ & $0.30(6)$ & $0.22(5)$ \\
\hline & & $\mathrm{SCR}_{\mathrm{C}_{\text {conv }}}$ & 1.10 & & $0.27(7)$ & $0.74(8)$ \\
\hline & \multirow{2}{*}{ January 2010} & $\mathrm{SCR}_{\mathrm{H}_{\text {sexed }}}$ & 0.99 & 0.42 & & $0.82(5)$ \\
\hline & & $\mathrm{SCR}_{\mathrm{C}_{\text {sexed }}}$ & 0.96 & 0.96 & 1.22 & \\
\hline \multicolumn{7}{|c|}{$95 \%$ confidence limit } \\
\hline \multirow[t]{7}{*}{ Holstein } & \multirow[t]{4}{*}{ August 2009} & $\mathrm{SCR}_{\mathrm{H}_{\text {conv }}}$ & & \multirow[t]{4}{*}{$0.61,0.74$} & $-0.41,0.00$ & $-0.42,0.32$ \\
\hline & & $\mathrm{SCR}_{\mathrm{C}_{\text {conv }}}$ & & & $-0.28,0.13$ & $-0.27,0.45$ \\
\hline & & $\mathrm{SCR}_{\mathrm{H}_{\text {sexed }}}$ & & & & $0.47,0.87$ \\
\hline & & $\mathrm{SCR}_{\mathrm{C}_{\text {sexed }}}$ & & & & \\
\hline & \multirow[t]{3}{*}{ January 2010} & $\mathrm{SCR}_{\mathrm{H}_{\text {conv }}}$ & & \multirow[t]{3}{*}{$0.58,0.72$} & $-0.13,0.29$ & $-0.30,0.54$ \\
\hline & & $\mathrm{SCR}_{\mathrm{C}_{\text {conv }}}$ & & & $-0.10,0.29$ & $-0.25,0.54$ \\
\hline & & $\mathrm{SCR}_{\mathrm{H}_{\text {sexed }}}$ & & & & $0.47,0.89$ \\
\hline \multirow{3}{*}{ Jersey } & \multirow{3}{*}{ January 2010} & $\mathrm{SCR}_{\mathrm{C}_{\text {conv }}}$ & & \multirow{3}{*}{$0.05,0.81$} & $-0.70,0.88$ & $-0.26,0.93$ \\
\hline & & $\mathrm{SCR}_{\mathrm{H}_{\text {sexed }}}$ & & & & $-0.31,0.99$ \\
\hline & & $\mathrm{SCR}_{\mathrm{C}_{\text {sexed }}}$ & & & & \\
\hline
\end{tabular}

consecutive evaluation dates for $\mathrm{SCR}_{\mathrm{H}_{\text {conv }}}, \mathrm{SCR}_{\mathrm{C}_{\text {conv }}}$, $\mathrm{SCR}_{\mathrm{H}_{\text {sexed }}}$, and $\mathrm{SCR}_{\mathrm{C}_{\text {sexed }}}$, almost guaranteeing a positive relationship between runs with the same breeding type. Corresponding percentages for Jerseys were 80, 84, 76, and 86. Correlations between August 2009 and January 2010 evaluations (Table 5) were high (0.95 to 0.98) within each SCR category for both Holsteins and Jerseys (based on 22 to 1,676 bulls for Holsteins and 5 to 140 bulls for Jerseys). Correlations within semen type between heifers and cows were intermediate $(0.61$ to 0.78 for Holsteins and 0.50 to 0.88 for Jerseys; based on
20 to 254 and 4 to 20 bulls, respectively). For Holsteins, correlations were low for SCR within each parity status between different semen type $(-0.14$ to 0.22 ; based on 22 to 83 bulls) and for SCR when both semen type and parity status differed ( -0.05 to 0.16 ; based on 21 to 97 bulls). For Jerseys, correlations were intermediate for SCR within parity status but different semen types (0.39 to $0.72 ; 5$ to 7 bulls) and for August 2009 SCR based on sexed semen with January 2010 SCR based on conventional semen ( 0.38 and $0.82 ; 7$ and 3 bulls, respectively). Jersey correlations between August 2009 
Table 5. Correlations and 95\% confidence limits between August 2009 and January 2010 evaluations for service-sire conception rate (SCR) with number of bulls in parentheses by breed for 4 evaluation categories based on animal parity [nulliparous heifer $(\mathrm{H})$ or cow $(\mathrm{C})$ ] and type of semen used for breeding [conventional (conv) or sexed]

\begin{tabular}{|c|c|c|c|c|c|}
\hline \multirow[b]{2}{*}{ Breed } & \multirow{2}{*}{$\begin{array}{l}\text { August } \\
2009\end{array}$} & \multicolumn{4}{|c|}{ January 2010} \\
\hline & & $\mathrm{SCR}_{\mathrm{H}_{\text {conv }}}$ & $\mathrm{SCR}_{\mathrm{C}_{\text {conv }}}$ & $\mathrm{SCR}_{\mathrm{H}_{\text {sexed }}}$ & $\mathrm{SCR}_{\mathrm{C}_{\text {sexed }}}$ \\
\hline \multicolumn{6}{|c|}{ Correlation } \\
\hline \multirow[t]{4}{*}{ Holstein } & $\mathrm{SCR}_{\mathrm{H}_{\text {conv }}}$ & $0.96(227)$ & $0.64(231)$ & $0.02(83)$ & $0.05(21)$ \\
\hline & $\mathrm{SCR}_{\mathrm{C}_{\text {conv }}}$ & $0.61(254)$ & $0.96(1,676)$ & $0.08(97)$ & $0.17(22)$ \\
\hline & $\mathrm{SCR}_{\mathrm{H}_{\text {sexed }}}$ & $-0.14(73)$ & $-0.05(77)$ & $0.96(84)$ & $0.75(20)$ \\
\hline & $\mathrm{SCR}_{\mathrm{C}_{\text {sexed }}}$ & $0.16(25)$ & $0.22(28)$ & $0.78(23)$ & $0.98(22)$ \\
\hline \multirow[t]{4}{*}{ Jersey } & $\mathrm{SCR}_{\mathrm{H}_{\text {conv }}}$ & $0.98(14)$ & $0.75(20)$ & $0.39(5)$ & $0.04(5)$ \\
\hline & $\mathrm{SCR}_{\mathrm{C}_{\text {conv }}}$ & $0.50(16)$ & $0.95(140)$ & $0.14(6)$ & $0.53(7)$ \\
\hline & $\mathrm{SCR}_{\mathrm{H}_{\text {sexed }}}$ & $0.67(5)$ & $0.38(7)$ & $0.98(6)$ & $0.81(5)$ \\
\hline & $\mathrm{SCR}_{\mathrm{C}_{\text {sexed }}}$ & $0.82(3)$ & $0.72(7)$ & $0.88(4)$ & $0.97(5)$ \\
\hline \multicolumn{6}{|c|}{$95 \%$ confidence limit } \\
\hline \multirow[t]{4}{*}{ Holstein } & $\mathrm{SCR}_{\mathrm{H}_{\text {conv }}}$ & $0.95,0.97$ & $0.55,0.71$ & $-0.20,0.23$ & $-0.39,0.47$ \\
\hline & $\mathrm{SCR}_{\mathrm{C}_{\text {conv }}}$ & $0.53,0.68$ & $0.95,0.96$ & $-0.12,0.28$ & $-0.27,0.55$ \\
\hline & $\mathrm{SCR}_{\mathrm{H}_{\text {sexed }}}$ & $-0.36,0.09$ & $-0.27,0.17$ & $0.94,0.98$ & $0.45,0.89$ \\
\hline & $\mathrm{SCR}_{\mathrm{C}_{\text {sexed }}}$ & $-0.26,0.52$ & $-0.17,0.55$ & $0.53,0.90$ & $0.94,0.99$ \\
\hline \multirow[t]{4}{*}{ Jersey } & $\mathrm{SCR}_{\mathrm{H}_{\text {conv }}}$ & $0.94,0.99$ & $0.45,0.89$ & $-0.77,0.94$ & $-0.87,0.89$ \\
\hline & $\mathrm{SCR}_{\mathrm{C}_{\text {conv }}}$ & $-0.01,0.79$ & $0.93,0.97$ & $-0.76,0.85$ & $-0.41,0.91$ \\
\hline & $\mathrm{SCR}_{\mathrm{H}_{\text {sexed }}}$ & $-0.57,0.97$ & $-0.55,0.87$ & $0.78,1.00$ & $-0.34,0.98$ \\
\hline & $\mathrm{SCR}_{\mathrm{C}_{\text {sexed }}}$ & - & $-0.13,0.95$ & $-0.62,1.00$ & $0.51,1.00$ \\
\hline
\end{tabular}

SCR based on conventional semen with January 2010 SCR based on sexed semen were low (0.04 and 0.14; 5 and 6 bulls, respectively).

The $95 \%$ confidence ranges are shown in Table 5 also and indicate which of the 4 alternatives differ within each breed across evaluation date. As before, this confirms little overlap in the range in Holsteins, with the correlation between heifer and cow evaluations higher than the correlation between conventional and sexed semen evaluations. In Jerseys, the confidence ranges were too wide to draw similar conclusions, as expected after observing the same within evaluation runs.

Holstein cow and heifer inseminations were combined in the model to derive a single SCR using all conventional semen data $\left(\mathbf{S C R}_{\mathbf{H}+\mathrm{C}_{\text {conv }}}\right)$. Correlations between $\mathrm{SCR}_{\mathrm{H}_{\text {conv }}}$ and $\mathrm{SCR}_{\mathrm{H}+\mathrm{C}_{\text {conv }}}$ were 0.83 and 0.81 for the August 2009 and January 2010 evaluations, respectively; correlations between $\mathrm{SCR}_{\mathrm{C}_{\text {conv }}}$ and $\mathrm{SCR}_{\mathrm{H}+\mathrm{C}_{\text {conv }}}$ were 0.97 for August 2009 and 0.96 for January 2010. These results were slightly less favorable than when the data were combined after deriving separate SCR. When Holstein cow and heifer inseminations with conventional semen were combined after deriving separate SCR evaluations, results were as expected based on correlations in Tables 4 and 5. Correlations between
$\mathrm{SCR}_{\mathrm{H}_{\text {conv }}}$ and $\mathrm{SCR}_{\mathrm{H}+\mathrm{C}_{\text {conv }}}$ were 0.83 for both August 2009 and January 2010 evaluations; correlations between $\mathrm{SCR}_{\mathrm{C}_{\text {conv }}}$ and $\mathrm{SCR}_{\mathrm{H}+\mathrm{C}_{\text {conv }}}$ were 1.00 for August 2009 and 0.99 for January 2010. Therefore, it appears that the prediction of conventional SCR for cows would not be improved much by examining the prediction of SCR for heifers, but the opposite use of data would be quite valuable. A similar comparison between the 2 sexed semen approaches showed a larger advantage for combining the SCR after calculation when compared with combining both heifer and cow data in the same model. In that case, it appears that the prediction of sexed semen SCR for heifers would not be improved much by examining the prediction of SCR for cows, but the opposite use of data would be quite valuable. These results appear to be due simply to the number of inseminations available in each of the parity groups, and further study is needed due to the small sample size in 2 of the 4 alternatives.

\section{CONCLUSIONS}

Holstein heifer and cow SCR were highly related when SCR was based on either conventional or sexed semen. In constrast, low correlations between conventional and 
sexed semen SCR based on either Holstein heifer or cow inseminations indicated that fertility rankings differed considerably between semen types. Combining Holstein cow and heifer breedings with conventional inseminations into a single SCR evaluation was advantageous due to both an increase in number of publishable bulls and an increase in reliability. Separate SCR evaluations are needed for conventional and sexed semen. Limited results were available for Jerseys, so insufficient evidence existed to suggest that the relationships among semen types and parities differed from Holsteins.

\section{ACKNOWLEDGMENTS}

The cooperation of the AgriTech Analytics (Visalia, CA), AgSource Cooperative Services (Verona, WI), and Dairy Records Management Systems (Raleigh, $\mathrm{NC}$, and Ames, IA) in supplying reproductive reports is acknowledged. The National Association of Animal Breeders (Columbia, MO) developed and coordinated the marketing codes used for designating type of semen used for breedings. Suggestions for the manuscript initiated by staff of the Animal Improvement Programs Laboratory (Beltsville, MD) and by anonymous reviewers for the Journal of Dairy Science were helpful.

\section{REFERENCES}

Abdel-Azim, G. 2010. Effect of synchronization and semen sorting on artificial insemination bull fertility. J. Dairy Sci. 93:420-425.

Animal Improvement Programs Laboratory. 2009. Listing of format 5, reproductive record, revision 1.2. Accessed Sept. 24, 2010. http:// aipl.arsusda.gov/formats/fmt5.html.
Calo, L. L., R. E. McDowell, L. D. VanVleck, and P. D. Miller. 1973. Genetic aspects of beef production among Holstein-Friesians pedigree selected for milk production. J. Anim. Sci. 37:676-682.

Clay, J. S. 1987. How ERCR's will be computed and published. Dairy Genetics and Reproductive Management Cow College. Mimeo., Virginia Polytechnic Inst. and State Univ., Blacksburg, VA.

DeJarnette, J. M., R. L. Nebel, and C. E. Marshall. 2009. Evaluating the success of sex-sorted semen in US dairy herds from on farm records. Theriogenology 71:49-58.

Kuhn, M. T., and J. L. Hutchison. 2008. Prediction of dairy bull fertility from field data: Use of multiple services and identification and utilization of factors affecting bull fertility. J. Dairy Sci. 91:2481-2492.

Kuhn, M. T., J. L. Hutchison, and H. D. Norman. 2008. Modeling nuisance variables for prediction of service sire fertility. J. Dairy Sci. 91:2823-2835.

Kuhn, M. T., J. L. Hutchison, and G. R. Wiggans. 2006. Characterization of Holstein heifer fertility in the United States. J. Dairy Sci. 89:4907-4920.

Norman, H. D., J. L. Hutchison, and R. H. Miller. 2010. Use of sexed semen and its effect on conception rate, calf sex, dystocia, and stillbirth of Holsteins in the United States. J. Dairy Sci. 93:38803890 .

Norman, H. D., J. L. Hutchison, and J. R. Wright. 2008a. Sire conception rate: New national AI bull fertility evaluation. AIPL Res. Rep. SCR1 (7-08). Accessed Sept. 24, 2010. http://aipl.arsusda. gov/reference/arr-scr1.htm.

Norman, H. D., J. L. Hutchison, J. R. Wright, and S. M. Hubbard. 2008b. A national sire fertility index. Pages $45-52$ in Proc. Dairy Cattle Reprod. Counc. Conf., Omaha, NE. Dairy Cattle Reprod. Counc., Hartland, WI.

Schenk, J. L., D. G. Cran, R. W. Everett, and G. E. Seidel Jr.. 2009. Pregnancy rates in heifers and cows with cryopreserved sexed sperm: Effects of sperm numbers per insemination, sorting pressure and sperm storage before sorting. Theriogenology 71:717-728.

Seidel, G. E., Jr., and J. L. Schenk. 2002. Field trials with sexed, frozen bovine semen. Page 64-69 in Proc. 19th Technol. Conf. on Artificial Insemination and Reproduction. Natl. Assoc. Animal Breeders, Columbia, MO.

Skjervold, H., and J. W. James. 1979. Causes of variation in the sex ratio in dairy cattle. Z. Tierz. Züchtungsbiol. 95:293-305.

Weigel, K. A. 2006. Prospects of improving reproductive performance through genetic selection. Anim. Reprod. Sci. 96:323-330. 